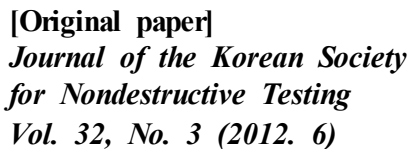

\title{
Acoustic Emission Monitoring of Lightning-Damaged CFRP Laminates during Compression-after-Impact Test
}

\author{
Jae-Ha Shin* and Oh-Yang Kwon**†
}

\begin{abstract}
Carbon-fiber reinforced plastic(CFRP) laminates made of nano-particle-coated carbon fibers and damaged by a simulated lightning strike were tested under compression-after-impact(CAI) mode, during which the damage progress due to compressive loading has been monitored by acoustic emission(AE). The impact damage was induced not by mechanical loading but by a simulated lightning strike. Conductive nano-particles were coated directly on the fibers, from which CFRP coupons were made. The coupon were subjected to the strikes with a high voltage/current impulse of 10 40 kA within a few $\mu$ s. The effects of nano-particle coating and the degree of damage induced by the simulated lightning strikes on $\mathrm{AE}$ activities were examined, and the relationship between the compressive residual strength and $\mathrm{AE}$ behavior has been evaluated in terms of $\mathrm{AE}$ event counts and the onset of $\mathrm{AE}$ activity with the compressive loading. The degree of impact damage was also measured in terms of damage area by using ultrasonic C-scan images. The assessment during the CAI tests of damaged CFRP showed that $\mathrm{AE}$ monitoring appeared to be useful to differentiate the degree of damage hence the mechanical integrity of composite structures damaged by lightning strikes.
\end{abstract}

Keywords: Carbon-Fiber Reinforced Plastic(CFRP), Electrical Conductivity, Lightning-Strike Damage, Nano-Particle Coating, Compression-after-Impact(CAI)

\section{Introduction}

Composite materials are increasingly used in aircraft structures because of their high specific stiffness and strength, good fatigue and corrosion resistance [1]. Recently, the application of carbon-fiber reinforced plastics in commercial airframes becomes in reality even for primary structures such as fuselage as well as main wings. Excellent specific properties are the major driving forces to structural application of CFRP, but the sensitivity of laminated composites to impact loading in the thickness direction has been a serious obstacle to more widespread use of this class of materials. This is because the energy dissipated during impact is mainly absorbed by a combination of matrix cracking, fiber fracture, and fiber-matrix debonding, thus leading to significant reductions in the loadcarrying capability of the material. In particular, compressive strength of brittle composite system is reduced remarkably after impact loading such as tool dropping and/or low-speed foreign object crashing [2]. Therefore, the damage tolerance becomes a major concern of reliability assessment. Since these types of damage are virtually invisible, the evaluation of residual strength under the CAI condition has been considered as a critical step in damage-tolerant design of numerous composite structures [3].

Another issue newly raised due to the use of composites in commercial airframe is their

[Received: April 13, 2012, Revised: May 21, 2012 / June 11, 2012, Accepted: June 15, 2012] *Department of Mechanical Engineering, Graduate School, Inha University, **Department of Mechanical Engineering, Inha University, 253 Yonghyun-dong, Incheon, 402-751, Korea †Corresponding Author: okwon@inha.ac.kr 
vulnerability to lightning-strike damage. Every commercial airplane can be exposed to lightning strikes on average about twice a year [4]. With composites employed as the major structural materials for fuselage, a serious concern about the lightning-strike damage becomes in reality due to the poor electrical conductivity of composites comparing to that of aluminum alloys [5]. When the fuselage is exposed to lightning strike, they shall suffer direct damages, such as puncture, spark propagation, local heating effect as well as indirect damages such as electromagnetic interference. If the external pressure acts on the surface of damaged area of fuselage, it will increase the severity of damages due to pressure from outside than the surface of the normal area. A study found that CFRP laminates made of carbon fibers coated with conductive nano-particles could reduce the lightning-strike damage by increased electrical conductivity [6].

In this study, CFRP coupons previously subjected to a simulated lightning strike were tested under the CAI condition and the damage progress due to compressive loading was monitored by acoustic emission (AE) activity.

\section{Experiments}

\subsection{Specimen and Experimental Setup}

Three types of materials were tested; woven-CFRP laminates for the uncoated, the ITO $30 \%$ coated, and the ITO $40 \%$ coated. Uncoated woven-CFRP coupons were prepared from a plain weave, dry graphite fabric (BMS 9-8 3K-70-PW, Pacific Composites) as a reference. For the ITO-coated CFRP coupons, there was no need to remove the resin by soaking it in MEK, which was the procedure for making UD-CFRP coupons designed by authors in the previous study [7]. The indium-tin oxides (ITO) nano-particles of $30 \%$ and $40 \%$ concentrations in colloidal suspension were spray-coated directly on the dry fabrics and dried. The ITO-coated carbon fiber fabrics were then placed between resin films on a hot press to produce nano-particles-coated woven-CFRP prepregs. The woven-CFRP laminated coupons were composed of 24 plies of the prepregs, with the lateral dimension of $100 \times 150 \mathrm{~mm}$ and the nominal thickness of $3.6 \mathrm{~mm}$. They were cured at a hot press by using the same resin films as used in producing the woven prepregs.

\subsection{Simulated Lightning Strikes and CAI Tests}

The impact damage was induced by the simulated lightning strikes with an impulse current generator (ICG). The center of CFRP coupons was shot by the high voltage-high current ICG at 10, 20, 30 and $40 \mathrm{kA}$ with a waveform of $8 \mu \mathrm{s}$ in rise time and $20 \mu \mathrm{s}$ in total duration. Damaged area of woven-CFRP coupons were virtually invisible even after the impulse current of $40 \mathrm{kA}$ was applied. The CAI test fixture was prepared based on ASTM D7137, but was slightly modified from previous experiences of compression tests of CFRP [8]. CAI tests were performed with a screw-driven mechanical test machine as shown in Fig. 1 where a CFRP coupon was in the CAI test jig. The crosshead speed was set to $1.25 \mathrm{~mm} / \mathrm{min}$ for all tests under displacement control.

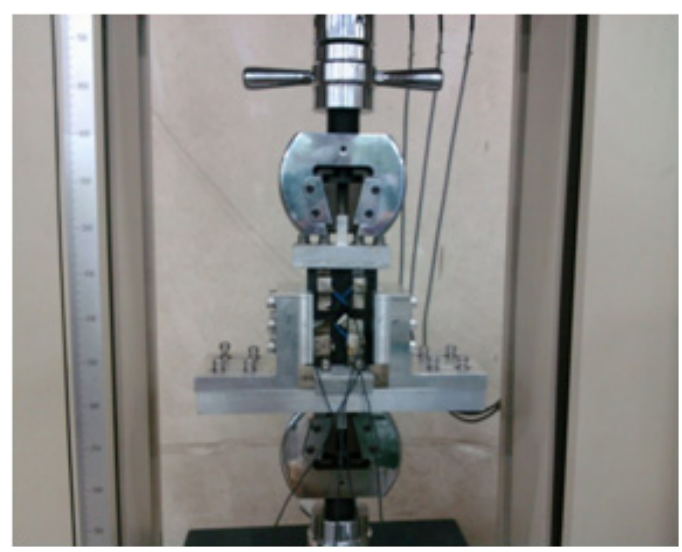

Fig. 1 CFRP coupons in place for CAI test 
Four small AE sensors (B1025, Digital Wave) were mounted at each quadrant, with their location $36 \mathrm{~mm}$ away from the corner and toward the center of the CFRP coupon. They were fixed to the surface by using a spring-assisted attachment and grease couplant.

Outputs of AE sensors were pre-amplified by $40 \mathrm{~dB}$ and filtered by a band-pass of $100 \mathrm{kHz} \sim 1.2 \mathrm{MHz}$, then processed and recorded by using AE data acquisition boards (MISTRAS 2001, PAC). Threshold was set at $35 \mathrm{~dB}$ for woven-CFRP coupons since it appeared to be losing some low amplitude AE signals arrived before the maximum compressive load was reached when the threshold of $45 \mathrm{~dB}$ after pre-amplifier had been applied for the tests of UD-CFRP coupons [8].

\section{Results and Discussion}

\subsection{Examination for the Degree of Damages}

Damaged areas of woven-CFRP coupons were visually examined after the CAI tests and the photographs are shown in Fig. 2. The left coupon was broken along the centerline containing the lightning-damaged area, whereas the right coupon was broken along a line slightly above the damaged area. However, the latter is commonly observed as acceptable failure modes under ASTM 7137 [8]. The broken surface of woven-CFRP coupons was not
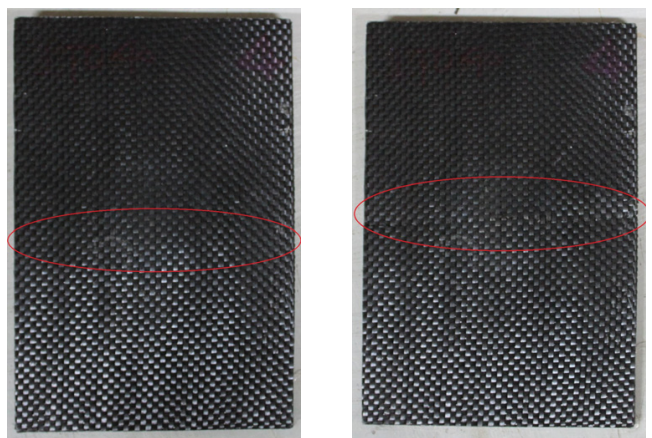

Fig. 2 Photographs of CFRP coupons after CAl tests

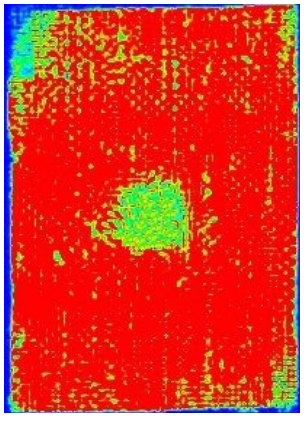

(a) Uncoated

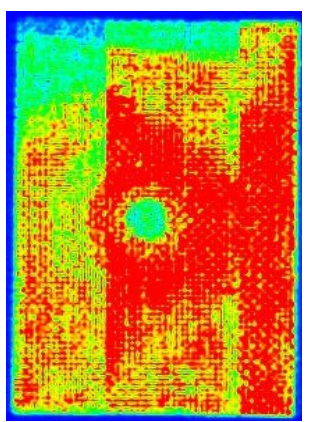

(c) $180^{\circ} \mathrm{ITO} 40 \%$ coated

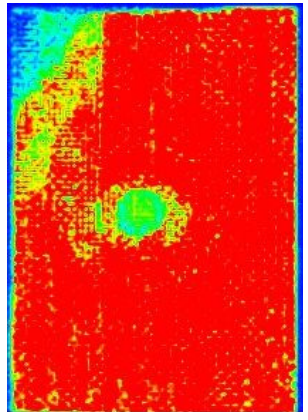

(b) ITO $30 \%$ coated

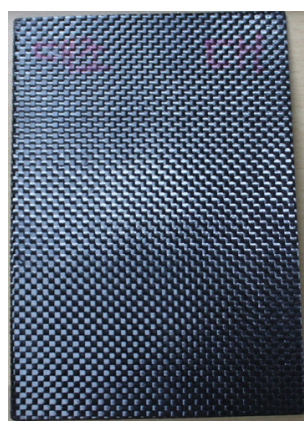

(d) Uncoated; visual
Fig. 3 Impact-damaged area examined by ultrasonic C-scan images for three types of CFRP coupons after the impulse current of $40 \mathrm{kA}$ was applied.; (d) is a visual image of damaged area for the uncoated shown as a reference.

as clear as that of UD-CFRP coupons previously reported [8].

The ultrasonic C-scan images of the impact-damaged area of woven-CFRP coupons are shown in Fig. 3. They were measured by using an ultrasonic scanning unit with 64channel linear phased-array transducer working at the center frequency of $5 \mathrm{MHz}$ (Matrixeye EX, Toshiba) with a built-in function of area calculation. A visual image of damaged area for the uncoated is also shown (d) as a reference. The impact-damaged area was the largest for the uncoated, intermediate for the ITO 30\% coated, and the smallest for the ITO $40 \%$ coated. The damaged area increased with increasing level of impulse current applied. Although the impactdamaged area was virtually invisible and much 
smaller than those appeared in UD-CFRP coupons, the overall trend was generally the same.

\subsection{Evaluation by AE Monitoring}

In Fig. 4, the primary data obtained during the CAI tests are shown as the relationship

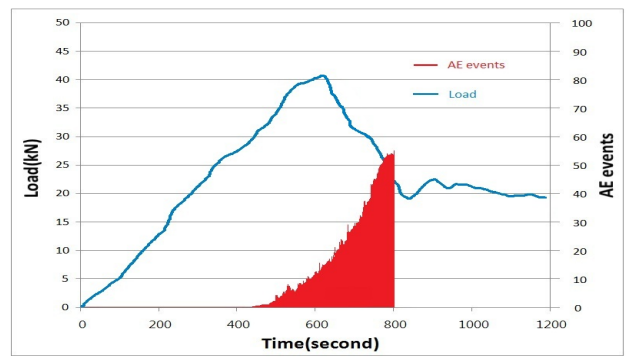

(a) Uncoated and $10 \mathrm{kA}$

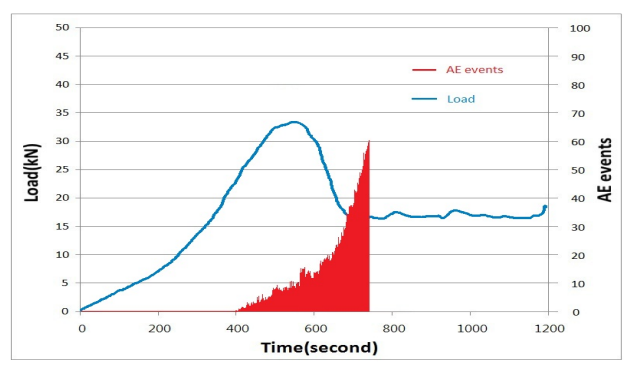

(b) Uncoated and $20 \mathrm{kA}$

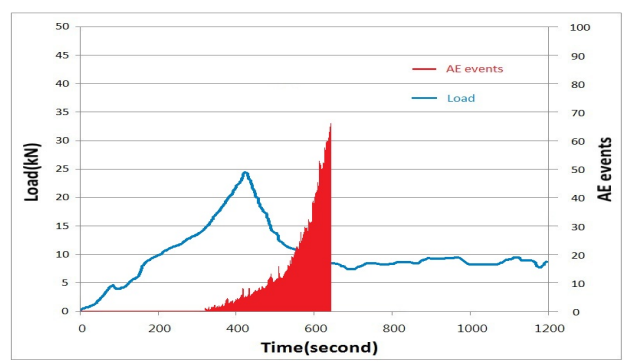

(c) Uncoated and $30 \mathrm{kA}$

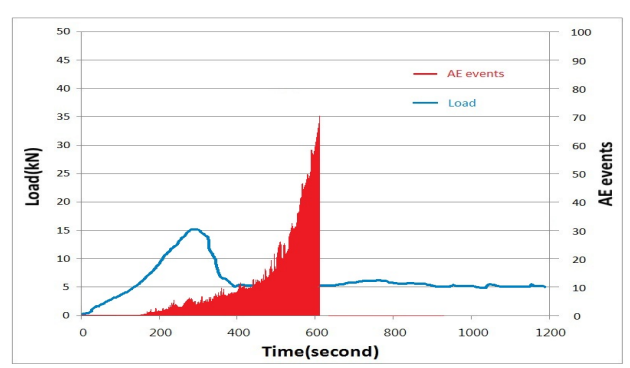

(d) Uncoated and $40 \mathrm{kA}$

Fig. 4 Relationship between load and $A E$ events with time for uncoated CFRP between compressive load and $\mathrm{AE}$ events with time for the uncoated, whereas the same data are shown in Fig. 5 for the ITO $40 \%$ coated. For both cases AE activity started earlier with the increasing level of impulse current applied, which corresponds to the severity of impact damage, but the onset of $\mathrm{AE}$ activity was

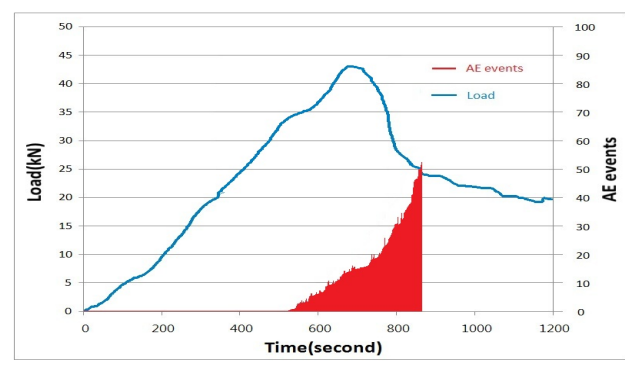

(a) ITO $40 \%$ coated and $10 \mathrm{kA}$

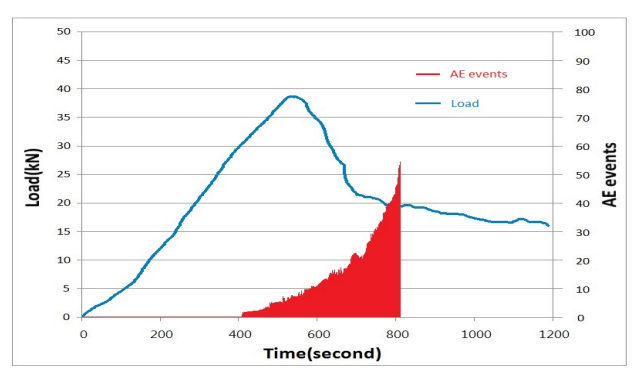

(b) ITO $40 \%$ coated and $20 \mathrm{kA}$

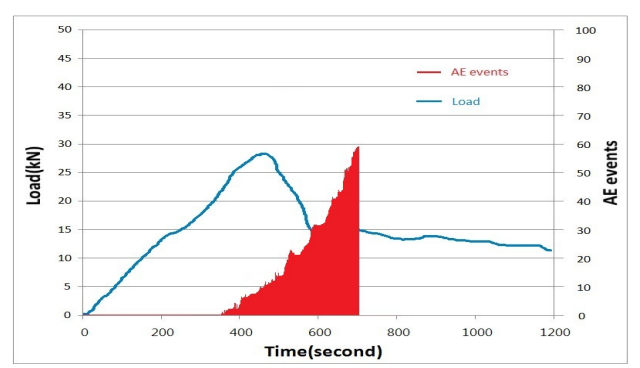

(c) ITO $40 \%$ coated and $30 \mathrm{kA}$

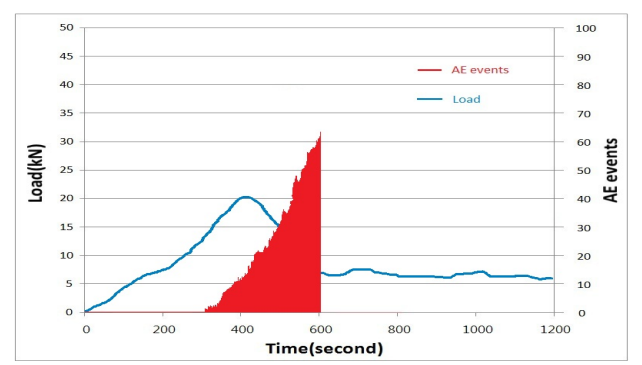

(d) ITO $40 \%$ coated and $40 \mathrm{kA}$

Fig. 5 Relationship between load and $A E$ events with time for ITO $40 \%$ coated CFRP 
significantly delayed with the ITO $40 \%$ coated in Fig. 5 regardless of the level of impulse current applied.

The maximum and the residual compressive strengths were also lower for the uncoated and damaged than for the ITO $40 \%$ coated and damaged. This is because higher degree of damage was induced at the same level of impulse current for the uncoated CFRP having lower electrical conductivity. On the other hand, more $\mathrm{AE}$ events were observed overall with increasing level of impulse current applied.

It appeared that the severe damage induced by stronger electrical shocks produced more sources of $\mathrm{AE}$ when the coupons were tested under CAI test mode. It becomes even clearer if one can combine the relationship between the maximum compressive strength and the level of impulse current given in Fig. 6, and the

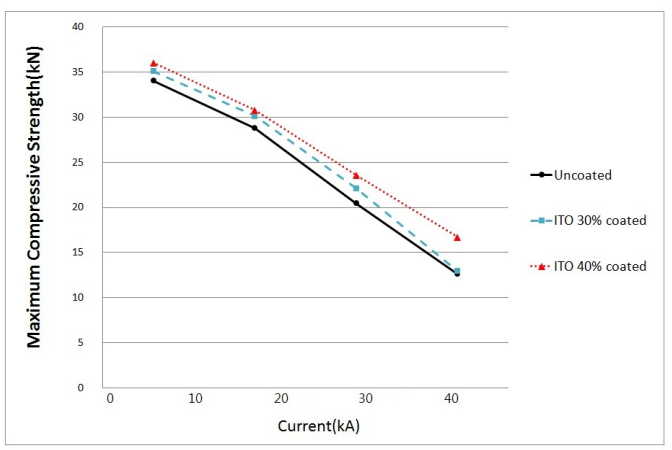

Fig. 6 Relationship between compressive strengths and the levels of impulse current

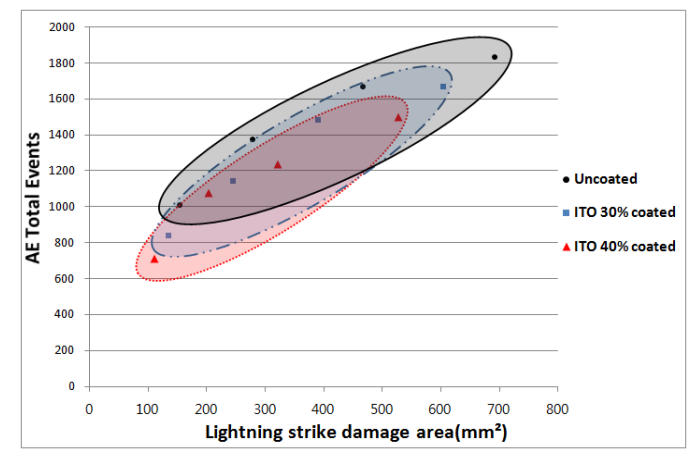

Fig. 7 Relationship between $\mathrm{AE}$ total events and the impact-damaged area impact-damaged area measured by ultrasonic $\mathrm{C}$-scan in Fig. 3. It could also be shown as the direct relationship between the damaged area and $\mathrm{AE}$ total events as given in Fig. 7.

In Fig. 6, the relationship between the maximum compressive strengths and the level of impulse current are shown for woven-CFRP. The maximum compressive strength appeared to be almost inversely proportional with the level of impulse current applied for all types of CFRP coupons; the uncoated, the ITO $30 \%$ coated, and the ITO $40 \%$ coated. At the same level of impulse current applied, the uncoated showed always the lowest strength whereas the ITO $40 \%$ coated showed the highest. There has been a similar trend observed for UD-CFRP coupons, although the maximum compressive strength was generally lower than the data shown here for woven-CFRP coupons [7].

The overall AE activity for each type of CFRP coupons are summarized in Fig. 7 in terms of $\mathrm{AE}$ total events versus the impactdamaged area for three different conditions of CFRP's in terms electrical conductivity. AE event counts appeared to be almost proportional to the impact-damaged area, which is again proportional to the level of impulse current applied for both types of CFRP coupons. The good correlation between $\mathrm{AE}$ events and the impact-damaged area induced by the impulse current can be utilized as a useful indicator of the degree of lightning-strike damage in composite airframes.

The relationship between $\mathrm{AE}$ total events and the maximum compressive strength with the level of impulse current applied is shown in Fig. 8 for woven-CFRP coupons. With increasing level of impulse current, $\mathrm{AE}$ total events increased regardless of the condition of CFRP coupons, whereas the maximum compressive strength decreased. A similar behavior was observed for UD-CFRP coupons and reported elsewhere [7]. Therefore, smaller counts of $\mathrm{AE}$ 


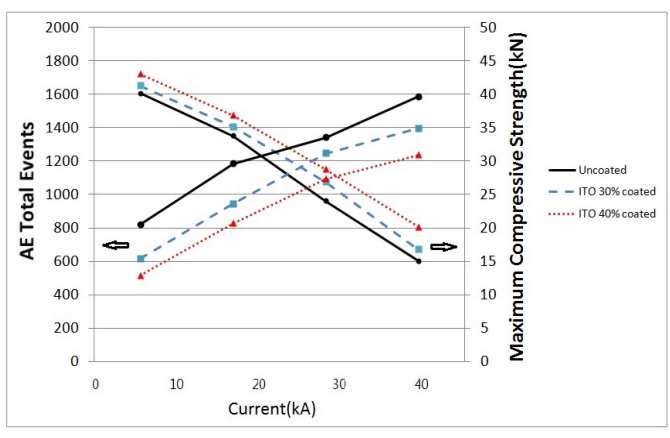

Fig. 8 Relationship between compressive strength and total $\mathrm{AE}$ counts

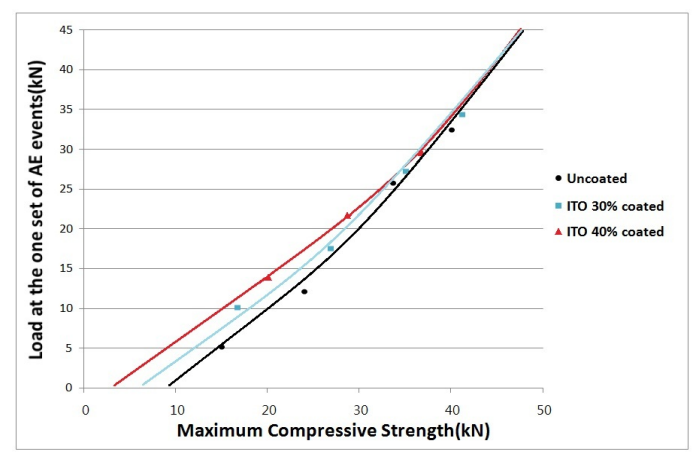

Fig. 9 Relationship between compressive strengths and the stress level of $A E$ counts initiation

total events implied smaller impact-damaged area and the higher maximum compressive strength.

In Fig. 9, the stress level at which $\mathrm{AE}$ activity started were calculated from the data shown in Figs. 4 and 5 correlated with the maximum compressive strength for each condition of woven-CFRP coupons. The onset of $\mathrm{AE}$ activity was based on the detected of $\mathrm{AE}$ events with the pre-determined threshold level. Since the maximum compressive strength appeared almost inversely proportional to the levels of impulse current as shown in Fig. 6, the lower maximum compressive strength means higher degree of the impact-damage. The lower left part of Fig. 10 represents this condition. The stress level at the onset of AE activity appeared much lower for the uncoated than for the ITO $40 \%$ coated. On the other hand, the upper right part of Fig. 10 represents the higher maximum compressive strength, hence lower degree of the impact-damage. In this case, the difference between different conditions of woven-CFRP was smaller. A similar behavior was observed for UD-CFRP coupons [7]. Therefore, this could be another useful indicator of the degree of damage induced by lightning strikes in composite airframes.

\section{Conclusions}

AE activity of CFRP coupons made of nano-particles-coated carbon fibers and then subjected to a simulated lightning strike by using a high voltage-high current impulse current generator was monitored under CAI test mode. AE data were evaluated in terms of the level of impulse current applied to simulate the lightning strike, hence the degree of impact-damage and the maximum compressive strength measured by the CAI tests. Coating of ITO nano-particles up to $40 \%$ in colloidal suspension appeared to be an effective means to prevent from lightning-strike damage in composite airframes. Compressive strength after the impact has close correlation with the level of impulse current applied and the lightning-strike damaged area. A good correlation between $\mathrm{AE}$ total events and the impact-damaged area induced by the impulse current applied can be utilized as a useful indicator of the degree of lightning-strike damage in composite airframes. The correlation between the maximum compressive strength and the stress level at the onset of AE activity could be another useful indicator of the degree of lightning-strike damage.

\section{Acknowledgement}

This work was supported by Inha University Research Grant. 


\section{References}

[1] J. R. Kollgaard and S. G. LaRiviere, "NDE challenges with future commercial aircraft - a Boeing perspective," Review of Progress in Quantitative NDE, Vol. 27, pp. 23-28 (2008)

[2] F. Aymerich and P. Priolo, "Characterization of fracture modes in stitched and unstitched cross-ply laminates subjected to low-velocity impact and compression after impact loading," International J. of Impact Engineering, Vol. 35, pp. 591-608 (2008)

[3] I. Ohsawa, I. Kimpara, K. Kageyama, T. Suzuki and A. Yamashita, "AE characterization of compressive residual strength of impact-damaged CFRP laminates," Progress in Acoustic Emission VII, JSNDI, pp. 511-516 (1994)

[4] F. A. Fisher, J. A. Plumer and R. A. Perala, Aircraft Lightning Protection Handbook, Federal Aviation Administration, DOT/FAA/CT-89/22, September (1989)
[5] J. Guo, Y. Tang, F. Liang, Z. Zhao, D. Firsich and J. Fielding, "Carbon nanofiber paper for lightning strike protection of composite materials," Composites Part B: Engineering, 41(2) pp. 192-198 (2010)

[6] S.-W. Seo, M.-S. Ha, O.-Y. Kwon and H.-S. Choi, "Improvement of electrical conductivity of carbon-fiber reinforced plastics by nano-particles coating," $J$. of the Korean Soc. for Composite Materials, pp. 222-227 (2010)

[7] J. -H. Shin, O. -Y. Kwon and S. -W. Seo, "Acoustic emission monitoring of compression-after-impact test of nanoparticles coated CFRP damaged by simulated lightning strikes," Journal of the Korean Society for Nondestructive Testing, Vol. 31, pp. 62-67 (2011)

[8] ASTM D7137-07, "Standard test method for compressive residual strength properties of damaged polymer matrix composite plates," American Soc. for Testing and Materials (2007) 